\title{
Vulnerabilidad y gestión del riesgo de desastres frente al cambio climático en Piura, Perú*
}

\author{
Recibido: 26 de marzo de 2020 - Aprobado: 24 de abril de 2020 \\ https://doi.org/10.22395/seec.v23n54a5
}

Hildegardo Córdova Aguilar**

\section{RESUMEN}

El cambio climático trae grandes desafíos que de alguna manera afectan el desarrollo sostenible de la vida en la tierra. No solamente se trata de los incrementos de temperatura que, según pronósticos especializados, llevarán a la desaparición de los glaciares tropicales con temperaturas de hasta $48{ }^{\circ} \mathrm{C}$ en los trópicos, sino de los impactos de esos incrementos, como son lluvias torrenciales, desertización, inundaciones, pérdida de cultivos, incremento de enfermedades, escasez de agua dulce, etc. Este estudio tiene como objetivo identificar vulnerabilidades ambientales urbanas en algunas ciudades peruanas, tomando como caso a Piura, que viene sufriendo de manera recurrente los impactos desastrosos del fenómeno de El Niño (FEN) con inundaciones, interrupciones de las vías de comunicación y otros sucesos que afectan la calidad de vida de sus habitantes. La metodología empleada es analítica-deductiva basada en bibliografía variada y observaciones de terreno. Como resultado global se ha encontrado escasez de estrategias de resiliencia y de recuperación en favor de las poblaciones más vulnerables frente a los impactos del cambio climático.

\section{PALABRAS CLAVE}

Vulnerabilidad; gestión de riesgos; cambio climático; Piura; resiliencia; gobernanza.

\section{CLASIFICACIÓN JEL}

Q54, Q58, R1

\section{CONTENIDO}

Introducción; 1. La vulnerabilidad frente al cambio climático de los sistemas ambientales de la costa peruana; 2. Adaptabilidad y resiliencia; 3. Gestión del riesgo de desastres en el noroeste peruano: caso de Piura; 4. Políticas públicas del Perú frente al cambio climático y gestión de riesgos; 5. Conclusiones; Bibliografía.

- Este es un artículo de información y reflexión sobre el cambio climático, sus impactos y resiliencias urbanas, tomando como ejemplo el caso de la ciudad de Piura. Es producto del grupo de investigación sobre temas urbanos y desarrollo ambiental bajo la coordinación del autor.

*. Geógrafo, Universidad Nacional Mayor de San Marcos, Lima, Perú. Magíster en Geografía, Universidad de Texas, Austin, Estados Unidos. Doctor en Geografía, Universidad de Wisconsin, Madison, Estados Unidos. Profesor cesante de las universidades Nacional Mayor de San Marcos de Lima y Pontificia Universidad Católica del Perú. Actualmente asociado a la Sociedad Geográfica de Lima. Correo electrónico: hildegardocordova@gmail.com. Orcid: https://orcid.org/0000-0002-0502-5085 


\section{VULNERABILITY AND NATURAL DISASTERS RISK MANAGEMENT IN PIURA, PERU ABSTRACT}

Climate change brings big challenges that in one way or the other affect the sustainable development of life on earth. Not only regarding the increase in the earth's temperatures, that according to specialized prediction will lead to the disappearance of tropical glaciers with temperatures up to $48^{\circ}$ in tropics, but also the impact of those increments such as torrential rains, desertification, flooding, loss of crops, an increase in diseases, scarcity of sweet water, etc. This study has as its main objective to identify the urban environmental vulnerabilities of some Peruvian cities, taking as a case the city of Piura, which has been recurrently suffering the devastating effects of the El Niño-Southern Oscillation (ENSO) like flooding, interruption of communication routes, and other phenomena affecting the life quality of its inhabitants. The methodology employed in this work is analytical-deductive and it is based on a wide bibliography and terrain observations. As a global result, this study found a scarcity of resilience and recovery strategies in favour of the more vulnerable populations regarding the impacts of climate change.

\section{KEYWORDS}

Vulnerability; risks management; climate change; Piura; resilience; governance.

\section{JEL CLASSIFICATION}

Q54, Q58, R1

\section{CONTENT}

Introduction; 1 . The vulnerability of the environmental systems of the Peruvian coast in front of climate change; 2. Adaptability and resilience; 3. Risk management for disasters in the Peruvian northeast: the Piura case; 3.1 ; 4. Peruvian public policies for climate change and risks management; 5. Conclusions; Bibliography.

\section{VULNERABILIDADE E GESTÃO DO RISCO DE DESASTRES ANTE A MUDANÇA CLIMÁTICA EM PIURA, PERU \\ RESUMO}

A mudança climática traz grandes desafios que, de alguma forma, afetam o desenvolvimento sustentável da vida na terra. Não somente se trata do aumento da temperatura que, segundo previsões especializadas, levará ao desaparecimento dos glaciares tropicais com temperaturas de até $48^{\circ} \mathrm{C}$ nos trópicos, mas também dos impactos desse aumento, como são as chuvas intensas, a desertificação, as enchentes, a perda de lavouras, o aumento de doenças, a escassez de água doce etc. Este estudo tem o objetivo de identificar vulnerabilidades ambientais urbanas em algumas cidades peruanas, tomando como caso Piura, que vem sofrendo de maneira recorrente os impactos desastrosos do fenômeno de El Niño, com enchentes, fechamento das vias de comunicação e outros que afetam a qualidade de vida de seus habitantes. Utiliza-se de metodologia analítico-dedutiva, baseada em bibliografia variada e observações do solo. Como resultado geral, têm sido observadas escassas estratégias de resiliência e de recuperação em prol das populações mais vulneráveis ante os impactos da mudança climática.

\section{PALAVRAS CHAVE}

Vulnerabilidade; gestão de riscos; mudança climática; Piura; resiliência; governança.

\section{CLASSIFICAÇÃO JEL}

Q54, Q58, R1

\section{CONTEÚDO}

Introdução; 1. A vulnerabilidade ante a mudança climática dos sistemas ambientais do litoral peruano:

2. Adaptabilidade e resiliência; 3. Gestão do risco de desastres no noroeste peruano: caso de Piura;

4. Políticas públicas do Peru ante a mudança climática e gestão de riscos; 5. Conclusões; Bibliografia. 


\section{INTRODUCCIÓN}

El cambio climático o, mejor dicho, la variación climática, es un proceso que involucra un conjunto de manifestaciones en el tiempo que desestabilizan los parámetros establecidos para el clima de los lugares durante los ciclos anuales de temperaturas, precipitaciones y movimientos atmosféricos. Esto produce modificaciones en los ecosistemas y en la vida en general y que necesitan atención para mitigar sus efectos negativos (Banco Mundial, 2010; 2014).

La tierra se está calentando, según mostró un estudio de la National Oceanic and Atmospheric Administration (NOAA) en 2015. De acuerdo con esta agencia ya en ese año la temperatura promedio de la superficie terrestre a nivel mundial había subido a $1,33{ }^{\circ} \mathrm{C}$ comparada con el promedio del siglo XX (Hoffmann, 2016). Asimismo, la temperatura promedio de los océanos a nivel mundial fue $0,74{ }^{\circ} \mathrm{C}$ por encima del promedio de la misma en el siglo XX. Ya en el año 2014, Tim Wheeler publicó un reporte que señalaba lo que se venía sintiendo con respecto al clima. Menciona que varios estudios habían demostrado con claridad que había un incremento constante de la temperatura de la tierra que se venía produciendo desde mediados del siglo XIX. Esto fue aceptado por consenso en el quinto reporte del Intergovernmental Panel on Climate Change (IPCC) del año 2013, que señala con más del $95 \%$ de certeza que desde mediados del siglo XX el clima viene cambiando por las actividades humanas. Como consecuencia de esto se esperan temperaturas más altas, cambios en los patrones de lluvias y la ocurrencia de eventos meteorológicos extremos más frecuentes. En este contexto, al final del siglo XXI se espera que la temperatura media global sea unos $4,8^{\circ} \mathrm{C}$ más alta que el siglo anterior (Wheeler, 2014).

Este cambio climático no solo pone en riesgo los sistemas naturales y físicos, sino que al aumentar la temperatura y lluvias también aumenta el riesgo de enfermedades humanas. A eso se suma el hecho de que los cambios en los patrones de circulación del aire (viento) llevan a concentraciones de polvo atmosférico que son la causa de alergias (Liu et al., 2019) tan comunes en nuestros días. También hay consenso en que estos cambios climáticos afectarán con mayor intensidad a los más pobres, quienes tienen menos oportunidad de resiliencia y, por lo tanto, sus probabilidades de desarrollo sostenible también son frenadas (Banco Mundial, 2010). Un reporte de Stefanía Gozzer publicado en la BBC-News Mundo el 4 de diciembre 2019 señala que en América Latina ya se observan cuatro efectos del cambio climático: inundaciones, sequías, huracanes más intensos y subida del nivel del mar. A estos efectos se agrega la desaparición de los glaciares tropicales, como se evidencia en los Andes centrales, y que aumenta la vulnerabilidad de las poblaciones que necesitan agua para atender sus distintas necesidades. Ampliando cada uno de estos efectos se resalta que: 
a) Las inundaciones son fenómenos naturales causados por eventos naturales, sin embargo, su incidencia y riesgos asociados se vienen exacerbando por actividades humanas en los últimos cincuenta años. Las causas de este incremento de frecuencia e intensidad se interrelacionan con las fuerzas de la naturaleza en el aumento de la deforestación en las laderas expuestas a lluvias torrenciales, reclamación de tierras pantanosas, emisión de gases de efecto invernadero, ausencia de planificación, crecimiento desordenado y una deficiente infraestructura, especialmente de sistemas de desagües. Asimismo, está la ocupación de espacios propios de los lechos de quebradas, el depósito de desmontes y basuras en los lechos de ríos y la canalización inadecuada de sus cauces; todo lo cual aumenta las vulnerabilidades y riesgos asociados. Es importante hacer notar que el incremento de lluvias no solo produce inundaciones, sino deslizamientos de lodo que en Perú se denominan huaycos.

b) Las sequías también se hacen notorias en los últimos años. Mientras que las lluvias son abundantes en algunos lugares, en otros aparece una ausencia que afecta la producción de agua para la agricultura y para el consumo humano. Tal es el caso de Chile que viene arrastrando una sequía desde hace una década que afecta a siete de sus dieciséis regiones y que es considerada la peor de los últimos cincuenta años (Gozzer, 2019). También se habla de un corredor seco en América Central que recorre la costa aledaña al océano Pacífico donde vive el 90 \% de la población de esa región, se extiende a lo largo de $1.600 \mathrm{~km}$ desde Chiapas hasta Panamá. Se trata de una zona agrícola donde las sequías son casi normales a principios de año por la presencia del FEN, sin embargo, en los últimos años se han venido produciendo sequías y lluvias torrenciales que producen inundaciones y deslizamientos de tierra, lo que causa impactos económicos cuantiosos.

c) Los huracanes son una preocupación permanente en la región tropical de América. No existe un acuerdo unánime para señalar que su incremento en frecuencia sea una consecuencia del cambio climático. Sin embargo, se viene señalando que la velocidad de circulación del aire durante los huracanes está disminuyendo, y esto hace que los desplazamientos sean más lentos y, con ello, que las precipitaciones sean más acentuadas y de mayor duración. El resultado es que los impactos son más severos por las destrucciones de infraestructura e inundaciones que producen.

d) La subida del nivel del mar se viene notando en los últimos años como consecuencia, no solo del derretimiento de los glaciares en los polos, sino porque el calentamiento global viene produciendo incrementos de la temperatura del 
agua de los mares y océanos. El agua tiende a expandirse cuando absorbe calor. Sin embargo, este aumento del nivel del agua de los mares y océanos no es homogéneo. Basta ver que hay costas que han aumentado su superficie por retiro del mar como el caso del sur de España, mientras que hay otras como en el Caribe que muestran evidencias de elevaciones del nivel de agua.

Con excepción de los huracanes y la elevación del nivel del mar, todos los demás efectos se sienten en Piura, y su vulnerabilidad se incrementa a medida que la densidad poblacional también sube. Esta problemática lleva a que esta investigación tenga como objetivo averiguar porqué no se sienten las respuestas de los habitantes de Piura para disminuir sus vulnerabilidades y riesgos ante las variaciones climáticas, esto es, ¿qué impide la buena gestión de los riesgos? Responder a esta pregunta es importante porque nos permitirá orientar mejor los esfuerzos de resiliencia local en donde la población, empoderada de sus debilidades, ayude a trabajar en las estrategias de respuesta sostenibles a lo largo del tiempo.

La metodología seguida en este estudio es de tipo analítico-deductivo, es decir, se basa en el análisis de la bibliografía sobre los impactos de las ocurrencias de El Niño, las intervenciones del gobierno central y regional, las experiencias en otras ciudades peruanas y observaciones en el terreno de las formas de ocupación de los suelos considerados como inapropiados por su exposición a fenómenos naturales potencialmente desastrosos.

\section{LA VULNERABILIDAD FRENTE AL CAMBIO CLIMÁTICO DE LOS SISTEMAS AMBIENTALES DE LA COSTA PERUANA}

El antes Instituto Nacional de Recursos Naturales Inrena (2006), citando un trabajo del IPCC (2007), señala que la vulnerabilidad es el grado por el cual un sistema es susceptible o incapaz de enfrentarse a efectos adversos del cambio climático, incluidos la variabilidad y los extremos del clima. La vulnerabilidad se relaciona directamente con el carácter, la magnitud y la rapidez del cambio climático, así como con la variación a la que un sistema está expuesto, a su sensibilidad y capacidad de adaptación (Autoridad Autónoma de la Cuenca Hidrográfica Chira-Piura [AACHCP], 2005, p. 33).

La vulnerabilidad aplicada a poblaciones humanas no solo depende de factores externos tales como existencia de recursos, sino también de factores sociales endógenos. En este estudio se centrará la atención especialmente a los factores sociales. La apropiación de estrategias de adaptación, por lo tanto, depende de las opciones diversas que existen como valores y metas de la población (Sherwood, 
2013). Al respecto, Yohe y Tol (2002) señalan que se pueden identificar ocho criterios específicos que influencian la capacidad adaptativa de las comunidades frente a desastres: tecnología disponible, recursos naturales, estructura de las instituciones locales, capital humano, capital social, procesos utilizados por los tomadores de decisiones locales, percepción de la comunidad sobre el origen del problema y su severidad, y habilidad de la comunidad para distribuir el riesgo. Estos criterios son muy importantes para tener en cuenta cuando se revisan las ocurrencias de fenómenos naturales recurrentes, como es el caso del fenómeno El Niño en la costa peruana, y se buscan estrategias de resiliencia. Es necesario también anotar que crear una política de adaptación requiere un entendimiento de la vulnerabilidad en el ámbito de los hogares que forman la comunidad. Una forma de entender esto es examinar las actitudes de los miembros de hogares durante los eventos extremos, como son las inundaciones. En este caso, los hogares más pobres responden menos en sus intentos de salir adelante, tal vez porque tienen menos opciones que escoger para mejorar sus condiciones de vida. Una familia que vive en extrema pobreza centra su atención en sobrevivir y no puede intentar ampliar o diversificar sus opciones de bienestar. La teoría de la trampa de la pobreza (Banerjee y Duflo, 2012) indica que los hogares que viven en pobreza no tienen acceso a los recursos necesarios para salir de ella. Los procesos que los excluyen de esta posibilidad pueden diferir según la localización y pueden ser debidos a la opresión del gobierno, aislamiento geográfico, falta de acceso a mercados, enfermedades o patrones climáticos errantes. De tal manera que los recursos para sacar a una familia o comunidad de la pobreza varían en gran medida y, por lo tanto, es imperativo que los investigadores de la trampa de la pobreza entiendan las restricciones específicas para cada comunidad y encuentren los desafíos. En este sentido, tenemos a la pobreza como un factor importante en las estrategias de resiliencia que se propongan a poblaciones afectadas por desastres. Queda claro, entonces, que los eventos desastrosos afectan a los hogares en la trampa de pobreza en una forma tal que hacen más difícil su recuperación en el mediano y largo plazo. Las familias están indefensas contra tales riesgos. Los impactos en sus hogares llevan a debilitar o reducir la mano de obra del hogar, disminuir sus bienes productivos y vaciar las reservas de capital. Una persona debilitada por insuficiencia de comida, por ejemplo, no tiene la fuerza suficiente para cumplir eficientemente con su trabajo. Mientras que los más ricos pueden recuperarse más fácilmente de los desastres naturales, los más pobres siguen una dinámica negativa que, en lugar de ascender, se mantienen o se van cuesta abajo (Sherwood, 2013; Banco Mundial, 2014).

Queda claro también en este estudio que las vulnerabilidades y riesgos de desastres frente al cambio climático afectan a los seres humanos indistintamente 
de su sexo. Al respecto, ya hay estudios que mencionan que las mujeres están expuestas a mayores riesgos o son más vulnerables en las ciudades debido a su rol de madres y cuidadoras de los bienes del hogar, además de las cuestiones de higiene ante inundaciones, por ejemplo (Arana, Quezada y Clement 2016). ¿Qué consecuencias inmediatas se perciben con el cambio climático?

Una de las principales consecuencias asociadas al cambio climático es el incremento de la vulnerabilidad de desastres en poblaciones, agricultura, infraestructura y otros, producida ya sea por el incremento de las precipitaciones pluviales, mayores descargas hídricas en los ríos y quebradas, inundaciones en la costa y derrumbes en las laderas andinas o por las sequías que son recurrentes en diferentes sectores del territorio.

Todos estos desafíos al desarrollo que ofrece el clima aumentarán con los años por venir; y los impactos más inmediatos se sentirán a través de fenómenos meteorológicos extremos como sequías, olas de calor o inundaciones. La gente que es vulnerable hoy a los efectos del clima, será aún más vulnerable en el futuro porque lo que actualmente es considerado como evento extremo será algo normal en el futuro (Wheeler, 2014). La vulnerabilidad a las inundaciones, en este caso, se debe a la concurrencia de procesos naturales y actividades humanas, es decir, mientras que las inundaciones son originadas por factores naturales, las actividades humanas aumentan su potencial de producir daños en el medio físico natural y socioeconómico. En el caso del noroeste peruano, el Instituto Nacional de Evaluación de Recursos Naturales (Inrena) realizó un estudio de vulnerabilidad de la cuenca del río Piura integrando los mapas de sensibilidad hidrológica, geológica y geomorfológica y sensibilidad por conflictos de uso. Esto resultó en un diagnóstico de la vulnerabilidad física natural de la cuenca frente a la potencial ocurrencia de eventos naturales generadores de desastres, que fue ampliado por la Autoridad Autónoma de la Cuenca Hidrográfica Chira-Piura (AACHCP) en un estudio sobre adaptación al cambio climático de la cuenca del Piura en el año 2005. Aquí se estableció claramente que la vulnerabilidad frente a lluvias o sequías tenía una estrecha relación con los procesos de deforestación y prácticas agrícolas de secano desarrolladas especialmente en la zona de Yunga, que es la más frágil frente a sequías, dejando el suelo descubierto y expuesto a la erosión pluvial. También se dejó sentado que el análisis de vulnerabilidad es un paso previo necesario para complementar la planificación de la adaptación. 


\section{ADAPTACIÓN Y RESILIENCIA}

La adaptación ambiental es el conjunto de procesos mediante los cuales los sistemas naturales y humanos mantienen un equilibrio homeostático frente a las fluctuaciones del ambiente a corto plazo. La capacidad de adaptación es la habilidad de un sistema de ajustarse al cambio climático (y sus variaciones extremas) para moderar daños posibles, aprovecharse de oportunidades o enfrentar las consecuencias (Inrena, 2006). La resiliencia es la capacidad de los mismos sistemas de recuperar sus formas originales en el menor tiempo posible. Esta capacidad está en estrecha relación con el grado de deterioro de los procesos naturales y socioecológicos, es decir, cuando más deteriorados estén, la resiliencia será más baja hasta que el deterioro sea tan fuerte que se llegue a la rexistasia'. Una de las formas más importantes para reducir la vulnerabilidad ante el cambio climático es aumentar la resiliencia física del sistema. Los agricultores, por ejemplo, pueden invertir en conservación de suelos y agua en un intento para mantener la humedad del suelo. También pueden modificar los tiempos de plantar y cambiar las variedades de cultivos escogiendo aquellos resistentes al calor y a la sequía, adoptar nuevas variedades, cambiar los programas de cultivos y ganadería, y mudarse a actividades no agrícolas. Lo que contribuye mejor a la adaptación depende de los efectos específicos locales que el cambio climático tiene y tendrá, así como las condiciones agroclimáticas y factores socioeconómicos tales como el desarrollo de mercados. Aquellos que cumplan con estos criterios pueden ser considerados como "prácticas de agricultura inteligente al clima [climate smart agriculture]" (Asfaw, Coromaldi y Lipper, 2015, p. 2).

El incremento de la temperatura produce estrés en los cultivos, lo que disminuye su capacidad productiva, especialmente los localizados en la costa del sector central y occidental de los Andes y que se dirigen a la agroexportación. En la sierra, un incremento de temperatura resulta en cierto modo favorable porque permite que los cultivos se desarrollen más rápido y se extiendan a niveles más altos de los que actualmente alcanzan. Por otro lado, se aprecia el impacto negativo en los ecosistemas naturales que deben activar sus estrategias resilientes para sobrevivir. Insistir en la agricultura se debe a que este sistema juega un rol de primer orden en las adaptaciones, pues se trata de alimentar a las poblaciones para que puedan cumplir las funciones que les fueran asignadas.

El año 2007, el Centro Internacional para la Investigación del Fenómeno de El Niño (Ciifen) publicó un resumen de los impactos del cambio climático por sectores

Quienes estén interesados en profundizar el entendimiento de los procesos de resiliencia socioecológica, pueden ver el trabajo de Marco Janssen et al. (2006); y sobre adaptaciones pueden ver los artículos publicados en La Red bajo la coordinación de Fernando Briones (2012). 
y algunas propuestas de adaptación, que se muestran en la tabla 1 con algunas modificaciones.

Tabla 1. Impactos del cambio climático según sectores y algunas medidas de adaptación

\begin{tabular}{|c|c|c|}
\hline Sectores & Impactos & Medidas de adaptación \\
\hline 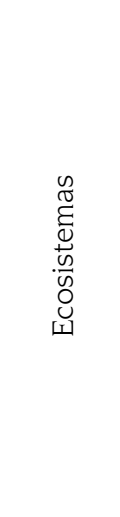 & $\begin{array}{l}\text { - Cambios en los rangos de distribución de } \\
\text { especies } \\
\text { - Pérdida de sincronización de eventos impor- } \\
\text { tantes (polinización, floración, dispersión, } \\
\text { migración) } \\
\text { - Mayor impacto de especies invasoras y pará- } \\
\text { sitos } \\
\text { - Incremento de estrés fisiológico de las especies } \\
\text { - Cambios de fertilidad y reproducción } \\
\text { - Cambios en la composición de las comunidades }\end{array}$ & $\begin{array}{l}\text { - Reducción de la degradación de los } \\
\text { ecosistemas } \\
\text { - Establecimiento de nuevas áreas pro- } \\
\text { tegidas } \\
\text { - Establecimiento de corredores biológi- } \\
\text { cos o ecológicos } \\
\text { Programas diseñados para apoyar alter- } \\
\text { nativas económicas a la tala extensiva del } \\
\text { bosque y disminuir la presión sobre usos } \\
\text { del suelo rural } \\
\text { - Inversión en restauración o conservación } \\
\text { de la infraestructura ecológica }\end{array}$ \\
\hline 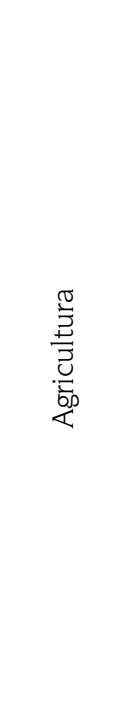 & $\begin{array}{l}\text { - Reducción de la oferta mundial de alimentos, } \\
\text { mayor riesgo de hambre } \\
\text { - Aumento de estrés térmico } \\
\text { - Mayor riesgo de degradación de tierras y } \\
\text { desertificación } \\
\text { - Mayor riesgo de salinización } \\
\text { - Irregularidad de periodicidad de estaciones } \\
\text { - Cambios en la calidad y cantidad de agua } \\
\text { disponible } \\
\text { - Modificación de las fechas de siembra y plan- } \\
\text { tación y de las variedades de cultivo } \\
\text { - Incremento de la incidencia de enfermedades } \\
\text { de plantas } \\
\text { - Reducción en la producción debido a olas de } \\
\text { calor y de frío } \\
\text { - Ampliación de la zonificación agroecológica }\end{array}$ & $\begin{array}{l}\text { - Nueva zonificación agroecológica } \\
\text { - Introducción de variedades resistentes } \\
\text { a las nuevas condiciones ambientales } \\
\text { - Ampliación de sistemas de irrigación } \\
\text { - Refuerzo de los sistemas para el control } \\
\text { de plagas y de enfermedades } \\
\text { - Manejo integral de suelos } \\
\text { - Uso de modelos de simulación de } \\
\text { cultivos } \\
\text { - Ampliación de la agricultura comercial } \\
\text { y disminución de la agricultura de } \\
\text { subsistencia } \\
\text { - Prácticas agroforestales }\end{array}$ \\
\hline
\end{tabular}




\begin{tabular}{|c|c|c|}
\hline Sectores & Impactos & Medidas de adaptación \\
\hline \multirow{7}{*}{$\frac{\pi}{2}$} & & $\begin{array}{l}\text { - Cumplimiento de las regulaciones de las } \\
\text { zonas de riesgo }\end{array}$ \\
\hline & $\begin{array}{l}\text { - Distribución temporal y espacial irregular del } \\
\text { recurso } \\
\text { - Intensificación de inundaciones y deslaves }\end{array}$ & $\begin{array}{l}\text { - Reevaluación de criterios de diseño } \\
\text { y seguridad de las estructuras para la } \\
\text { gestión del agua }\end{array}$ \\
\hline & - Cambios en los caudales hidrológicos & - Manejo integral de recursos hídricos \\
\hline & - Incremento de estrés hídrico & \multirow{2}{*}{$\begin{array}{l}\text { - Potenciación de prácticas ancestrales de } \\
\text { manejo de agua }\end{array}$} \\
\hline & - Deterioro de calidad del agua & \\
\hline & \multirow[t]{2}{*}{$\begin{array}{l}\text { - Mayor riesgo de contaminación de aguas } \\
\text { subterráneas }\end{array}$} & $\begin{array}{l}\text { - Protección de agua subterránea y planes } \\
\text { de restauración }\end{array}$ \\
\hline & & $\begin{array}{l}\text { - Mejoramiento de los sistemas de abas- } \\
\text { tecimiento de agua }\end{array}$ \\
\hline
\end{tabular}

- Aumento del nivel del mar con efectos significativos entre 2050 y 2080

- Riesgo para actividades económicas e infraes- • Manejo integral de las zonas costeras tructura ubicada cerca o al nivel del mar

- Intensificación de inundaciones

- Desplazamientos de población

- Planes de monitoreo y protección

- Salinización de las tierras bajas que afectaría a las fuentes de agua potable

- Regulaciones de acceso a las zonas de pesca

- Modificación del régimen de tormentas en las zonas costeras

- Aumento de erosión y alteración de la forma del perfil costanero

- Impactos negativos en biodiversidad costera

- Acuerdos internacionales para la protección del ambiente marino

- Prevención de la contaminación

- Mantenimiento y mejoramiento de la biodiversidad de las costas

- Fortalecimiento de los servicios de salud

- Problemas de seguridad alimentaria, con un consecuente aumento probable de los niveles de desnutrición en la población

- Aumento de la conciencia sobre el impacto del cambio climático en la salud humana

- Aumento de los casos de malaria y dengue

- Incremento de diarreas, cólera y otras enfermedades transmitidas por el agua

- Aumento de estrés térmico, enfermedades respiratorias y cutáneas, por olas de calor y frío

- Migración humana forzada debido a sequías, inundaciones y degradación ambiental

- Fortalecimiento del sistema de vigilancia para las enfermedades sensibles al clima

- Fomento de la investigación sobre "clima y salud"

- Implementación de un plan estratégico de educación y comunicación sobre "cambio climático y salud"

- Muertes y lesiones por inundaciones y desliza- • Establecimiento de canales de comumientos de terreno nicación regulares con organizaciones de la salud

Fuente: elaboración propia a partir de IPCC (2007). 
Esta propuesta es interesante en tanto señala algunas acciones frente a los impactos que deben ser tenidas en cuenta en la gestión del cambio climático. Como ya se indicó líneas arriba, este impacto se relaciona con el agua y en los aspectos sociales solo menciona a la salud. No dice nada sobre los aspectos socioculturales de las poblaciones afectadas y de sus estrategias de adaptación frente al cambio climático. Por lo tanto, es necesario insistir en que son los actores locales quienes deben tomar las decisiones de aplicación de los sistemas de adaptación al cambio climático en sus políticas de desarrollo y de acuerdo a sus propias necesidades.

\section{GESTIÓN DEL RIESGO DE DESASTRES EN EL NOROESTE PERUANO: CASO DE PIURA}

El riesgo de desastre es el factor que alude a la probable ocurrencia de un desastre como resultado de una compleja interacción entre un fenómeno potencialmente destructivo (amenaza ${ }^{2}$ ) y las condiciones de vulnerabilidad de las comunidades y su entorno económico. El riesgo es producto de dos factores: amenaza y vulnerabilidad que, cuando coinciden en un tiempo y espacio determinados, configuran el riesgo (AACHCP, 2005, p. 15). El desastre ocurre cuando las ocurrencias de estos fenómenos afectan directamente a los seres humanos ya sea en sus vidas, economía, infraestructura, etc.

Muchos temas ambientales se relacionan con riesgos endógenos. Así, las acciones y reacciones humanas pueden cambiar el hecho de que cosas buenas o malas ocurran. Los riesgos endógenos se dan en la idea de que los individuos tienen un cierto control sobre un conjunto de probabilidades y resultados que definen a las sociedades del mundo. Dentro de este marco es posible distinguir entre la autoprotección, que representa la inversión privada para aumentar la probabilidad de que ocurra una buena acción, y la autoseguridad, que son los gastos para reducir la severidad de una acción mala. En el caso del cambio climático, la autoprotección es conocida como mitigación y la autoseguridad, como adaptación. En la perspectiva endógena de riesgo, la mitigación y la adaptación son consideradas como dos estrategias de reducción de riesgos asociados con el cambio climático (Asfaw, Coromaldi y Lipper, 2015).

En el caso de Piura, el riesgo se asocia de alguna manera con el agua. Se trata de saber si se tiene mucha lluvia que produce inundaciones, derrumbes y destrucción de infraestructura física o muy poca lluvia que lleva a la sequía con las pérdidas de cultivos, escases de pastos, migraciones humanas, etc. En el departamento de Piura

Amenaza es el factor de ocurrencia de fenómenos atmosféricos, hidrológicos y geológicos en un tiempo y lugar determinados que por su severidad y frecuencia, pueden afectar adversamente a los seres humanos, estructuras y actividades (AACHCP, 2005, p. 15). 
y, especialmente, en la cuenca del río Piura, las lluvias se distribuyen normalmente de manera muy desigual con $27 \mathrm{~mm}$ en Bernal a $16 \mathrm{~m}$ de altitud hasta $1.240 \mathrm{~mm}$ en Huarhuar a $3.150 \mathrm{~m}$ de altitud. La temperatura media también se distribuye desigualmente desde $25^{\circ} \mathrm{C}$ en El Partidor (239 msnm) hasta $10,7^{\circ} \mathrm{C}$ en Arenales a $3.200 \mathrm{~m}$ de altitud (Inrena, 2006, p. 21). Durante el FEN 1982-1983, las lluvias se incrementaron de 1,5 a 5,3 veces en la cuenca alta del Piura. En el sector medio este incremento fue de 9,9 a 30,4 veces; y en el sector bajo el incremento fue de 8,5 a 212,2 veces (Inrena, 2006, p. 43). Estos incrementos extraordinarios rebasan la capacidad de carga de los cauces naturales y resultan en inundaciones que afectan territorios agrícolas y urbanos en la parte baja. El Gobierno Regional de Piura y la AACHCP tienen estudios y planes de mitigación de los riesgos, pero estos se dirigen principalmente a proteger la economía regional, es decir, la producción agropecuaria, pesca litoral, infraestructura de transporte y comunicaciones, etc. Sin embargo, aparece menor atención para atender las vulnerabilidades urbanas propiamente y a su población (gráfico 1).

\section{Gráfico 1. La cuenca del río Piura en el departamento de Piura}

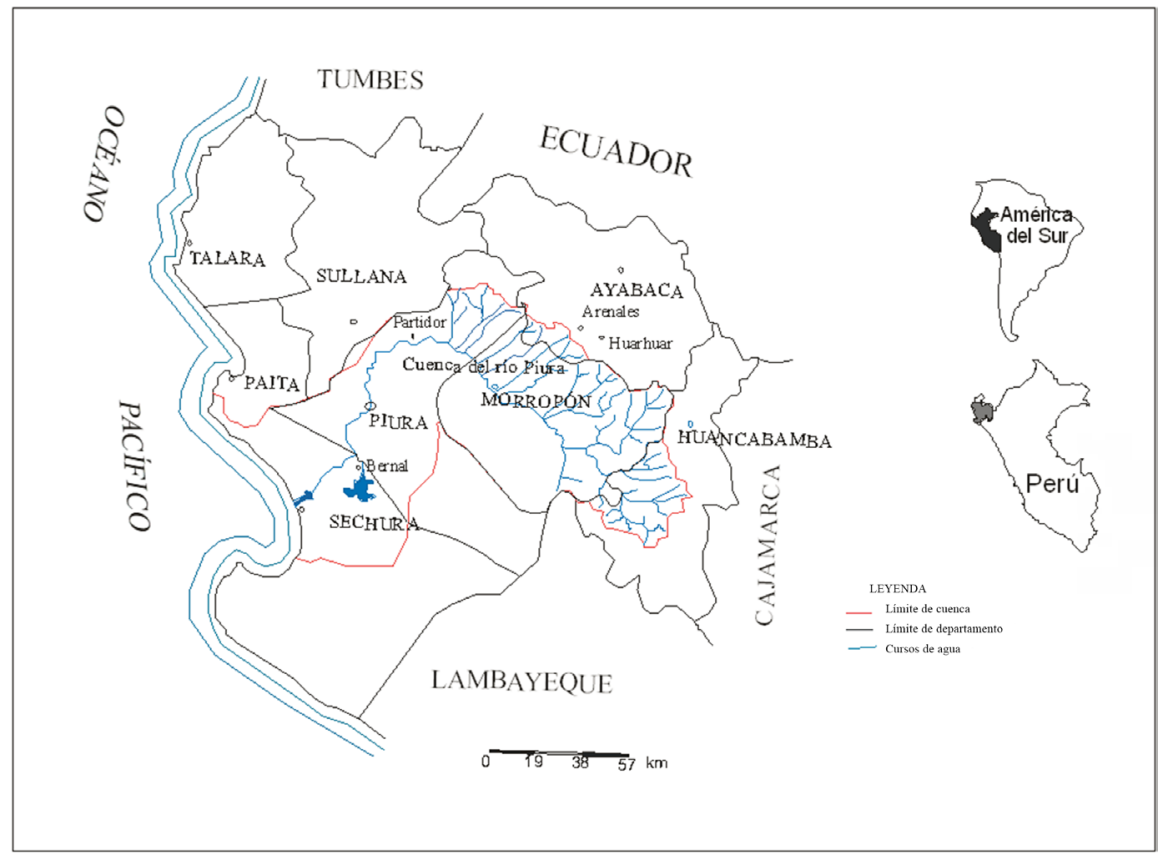

Fuente: elaboración propia.

3 El territorio del departamento de Piura tiene dos zonas completamente distintas desde el punto de vista morfológico. La costa, con un relieve casi plano (2-3\% de gradiente), comprende dos tercios del territorio y la sierra, de terreno accidentado y gradientes de hasta $100 \%$, cubre el tercio restante. La costa es la que soporta las inundaciones, especialmente el sector bajo que está desde la ciudad de Piura hasta el mar. 
Por eso, los reportes de respuesta ante los FEN se concentran mayormente en infraestructura física como recuperación de canales de riego, drenaje, canalización de los cauces de ríos, etc. En el caso de drenajes para recuperar suelos salinos, si bien se han realizado avances para disminuir la salinización de tierras agrícolas, todavía se necesitan más esfuerzos de mantenimiento, para controlar el crecimiento de plantas, como la totora (Typha dominguensis), en los lechos de canales que impiden el escurrimiento normal del agua. Este esfuerzo tiene más de cincuenta años y todavía no se ha logrado controlar. En 1975 el 61 \% del área agrícola tenía más de 12 mmhos/ cm, en 1990 había bajado a 36 \%. Esto se debió a la construcción en 1986 de canales de drenaje troncales y a nivel de parcelas (Inrena, 2006, p. 458). La salinización es la responsable de la pérdida de la capacidad productiva de los suelos en el sector bajo del valle de Piura, pérdida de la producción agrícola y efectos en la economía de miles de agricultores que dependen de sus parcelas para atender a sus familias.

La erosión de suelos es otro problema, especialmente en el sector medio y alto. La erosión se produce por la pluviosidad y la actividad fluvial. El suelo en toda su extensión está sometido a cambios constantes a través del tiempo, impulsados por el clima y por la acción humana. Los cambios en su estructura originan problemas directos en los componentes ambientales y en las actividades productivas directas (agricultura), así como problemas relacionados con el transporte y la deposición de sedimentos en las zonas bajas que colmatan los canales de riego. Especialmente preocupante es la deposición de lodo en el reservorio Poechos, que es la obra hidráulica más importante del departamento de Piura y está ubicado en el valle del río Chira, pero provee agua para el riego del Bajo Piura y para la población de la ciudad de Piura. Se construyó en los primeros años de la década de 1970 y en el año 2000 ya había perdido el 46 \% de su capacidad original. Los FEN de 1982-1983 y 1997-1998 aceleraron esta colmatación al punto que otros FEN en el futuro cercano pueden inutilizar este reservorio dejando sin agua a cerca del 70 \% de la tierra agrícola de los valles Chira y Piura (Inrena, 2006, p. 461) y a más de cuatrocientos mil personas de la ciudad metropolitana de Piura.

Entonces, queda claro que los problemas frente al cambio climático en el noroeste peruano, que incluye al departamento de Piura, se relacionan con el agua en donde para los habitantes urbanos resaltan las inundaciones.

\subsection{GESTIÓN DEL RIESGO EN LA CIUDAD DE PIURA}

En los últimos veinte años se viene sintiendo un mayor interés en la comunidad científica internacional por las implicancias del cambio climático en áreas urbanas, particularmente en países en vías de desarrollo, donde las ciudades están creciendo 
rápidamente y un alto porcentaje de sus habitantes son pobres y, por lo tanto, vulnerables a los eventos del clima (Tyler y Moench, 2012).

Varios estudios (Olajide y Lawanson, 2014) señalan que las ciudades en los países en desarrollo son muy vulnerables a los impactos de cambio climático, especialmente a las inundaciones. El incremento desorganizado de los asentamientos humanos en estas ciudades crea el ambiente propicio para las inundaciones debido a la pobre calidad de infraestructura y a que estas poblaciones se establecen en lugares más vulnerables ${ }^{4}$ que otros residentes con mejor poder adquisitivo. Como ya se mencionó líneas arriba, las poblaciones pobres tienen menor resiliencia ante los fenómenos climáticos. Entonces, cualquier trastorno climático que se presenta en estos lugares produce impactos negativos en la calidad de vida humana. Como bien señalan Olajide y Lawanson (2014), las inundaciones de áreas urbanas son tenidas como los mayores peligros que interrumpen la prosperidad, seguridad, infraestructura y modos de vida en los asentamientos humanos, particularmente en los países en desarrollo, lo que dificulta que los pobres puedan salir de la pobreza. Las inundaciones tienen efectos múltiples en los modos de vida de los pobres urbanos. Les afecta en la salud por la aparición de enfermedades relacionadas con el agua, les destruye la comida, les hace perder sus ingresos y producen deterioro de los servicios de higiene. Los centros educativos son cerrados durante los periodos de inundación, algunas personas no pueden ir a trabajar por periodos largos y eso resulta en interrupción de ingresos y hasta pérdidas de sus puestos de trabajo. Todos estos peligros, cuando se convierten en realidades, aplastan las esperanzas de desarrollo y en esas condiciones la resiliencia es muy baja.

En el caso de Piura, las lluvias son bienvenidas por los rurales porque traen agua para sus campos y pasto para sus animales. En cambio, son una preocupación para los urbanos, como la ciudad de Piura, en donde el incremento de la escorrentía del río produce inundaciones con destrucción de viviendas, formación de lagunas en las calles, proliferación de insectos, malos olores por la descomposición de la materia orgánica y malestar en la salud de sus habitantes. Siguiendo a Tyler y Moench (2012) los elementos-componentes de la resiliencia urbana pueden identificarse en tres grupos: sistemas, agentes e instituciones que se explican a continuación:

1. Los sistemas se refieren a infraestructura. Las ciudades requieren niveles elevados de infraestructura para cumplir con los servicios esenciales. También necesitan vincularse con otros sistemas a nivel regional que permiten el abastecimiento, como es el caso de comida, para lo cual dependen en los ecosistemas. A nivel

En el caso de la ciudad de Piura hay un asentamiento humano establecido en una zona baja que fue un antiguo pantano. Como es de esperarse, cada vez que hay lluvias intensas el lugar sufre por el empozamiento del agua. 
global, las ciudades se conectan por el comercio internacional, inversiones e importaciones que pueden tener efectos directos en el empleo y calidad de vida de sus habitantes. Entonces, estas redes de soporte son también elementos esenciales en la resiliencia urbana e incluye infraestructura física y ecosistemas, tanto dentro de la ciudad como en las áreas adyacentes y remotas que proveen servicios esenciales como es la producción de comida y el control de inundaciones. Si bien los administradores locales pueden tener poca influencia más allá de sus fronteras urbanas, sus sistemas pueden verse afectados enormemente por factores diversos en diferentes escalas y distancias. Por ejemplo, la distribución de la electricidad urbana depende de una central que puede estar distante. La pérdida de cosechas en alguna parte del mundo afecta las importaciones y precios a nivel local, lo cual perturba el bienestar humano. Asumir el riesgo que existe para que estos sistemas puedan fallar ante el estrés del cambio climático es crucial para entender sus interdependencias en donde la falla en uno afecta a los demás. Los sistemas resilientes aseguran que la funcionalidad se mantenga y que pueda ser restituida mediante las ligazones con los otros sistemas a pesar de sus fallas operacionales. En vez de depender de la fuerza de componentes individuales, los sistemas resilientes detienen su funcionalidad a través de la flexibilidad y diversificación de su dependencia funcional.

Aplicando la resiliencia a los sistemas de la ciudad de Piura, se tiene que trabajar en la recuperación de las vías de comunicación terrestre que se interrumpen por las lluvias e impiden el abastecimiento de comida y de bienes necesarios para el bienestar de la población. Asimismo, está la recuperación de la infraestructura de riego, control de plagas, drenaje de aguas de las zonas inundadas. Una síntesis de la resiliencia de sistemas se muestra en la tabla 2.

\section{Tabla 2. Resiliencia de sistemas}

\begin{tabular}{|c|c|c|c|}
\hline $\begin{array}{l}\text { Características } \\
\text { del sistema }\end{array}$ & Descripción de desempeño & $\begin{array}{l}\text { Como sería esto para el sistema de } \\
\text { abastecimiento de agua, como ejemplo }\end{array}$ & Otros ejemplos \\
\hline 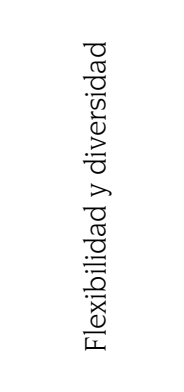 & $\begin{array}{l}\text { El sistema puede aten- } \\
\text { der las necesidades de } \\
\text { servicio bajo una gran } \\
\text { variedad de condiciones } \\
\text { climáticas. Los elemen- } \\
\text { tos vitales están espa- } \\
\text { cialmente distribuidos y } \\
\text { pueden sustituirse entre } \\
\text { sí, pero están funcional- } \\
\text { mente conectados. }\end{array}$ & $\begin{array}{l}\text { Fuentes de agua superficial y subte- } \\
\text { rránea, guardar el agua en la zona de } \\
\text { producción para usarla en tiempos } \\
\text { de sequía. } \\
\text { Estaciones de bombeo en sitios múl- } \\
\text { tiples con zonas de sobrelapamiento. } \\
\text { Gestión de la demanda para asegurar } \\
\text { que el agua sea usada eficientemente. } \\
\text { Flota expandible de tanques de agua. }\end{array}$ & $\begin{array}{l}\text { Transporte: modos y } \\
\text { capacidades múltiples } \\
\text { para el transporte de } \\
\text { bienes vitales y gente. } \\
\text { Abastecimento de co- } \\
\text { mida proveniente de di- } \\
\text { versas áreas geográficas. }\end{array}$ \\
\hline
\end{tabular}




\begin{tabular}{|c|c|c|c|}
\hline $\begin{array}{l}\text { Características } \\
\text { del sistema }\end{array}$ & Descripción de desempeño & $\begin{array}{l}\text { Como sería esto para el sistema de } \\
\text { abastecimiento de agua, como ejemplo }\end{array}$ & Otros ejemplos \\
\hline 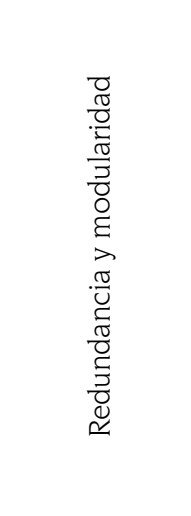 & $\begin{array}{l}\text { Capacidad extra para } \\
\text { atender servicios de } \\
\text { demanda inesperada } \\
\text { o eventos climáticos } \\
\text { extremos. } \\
\text { Los componentes del } \\
\text { sistema y sus interco- } \\
\text { nexiones proveen opcio- } \\
\text { nes múltiples o compo- } \\
\text { nentes sustituibles para } \\
\text { el envío de servicios. }\end{array}$ & $\begin{array}{l}\text { La capacidad de los reservorios ex- } \\
\text { cede la demanda en condiciones de } \\
\text { sequía. } \\
\text { La tasa de reposición del agua subte- } \\
\text { rránea excede la tasa de extracción. } \\
\text { Almacenamiento suficiente para aten- } \\
\text { der la variabilidad anual o cualquier } \\
\text { otra interrupción del abastecimiento. } \\
\text { Equipos de emergencia para atender } \\
\text { el bombeo del agua. } \\
\text { Sistemas de almacenamiento del } \\
\text { agua de lluvias para complementar el } \\
\text { abastecimiento de agua doméstica. }\end{array}$ & $\begin{array}{l}\text { Transporte: múltiples } \\
\text { rutas de acceso. } \\
\text { Comunicaciones: to- } \\
\text { rres de transmisión } \\
\text { redundantes. } \\
\text { Energía: generadores } \\
\text { auxiliares para servicios } \\
\text { cruciales. } \\
\text { Comida y medicinas: } \\
\text { mantener un alto stock/ } \\
\text { balance para casos de } \\
\text { disrupciones. }\end{array}$ \\
\hline 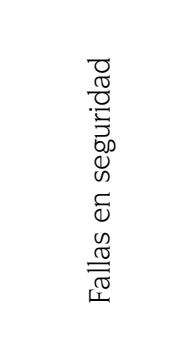 & $\begin{array}{l}\text { Falla en una parte del } \\
\text { sistema no llevará a } \\
\text { fallas en cascada de } \\
\text { otros elementos o sis- } \\
\text { temas relacionados. El } \\
\text { sistema vital de envío } \\
\text { puede mantenerse aun } \\
\text { en casos de fallas. }\end{array}$ & $\begin{array}{l}\text { Protección y monitoreo de la calidad } \\
\text { de la fuente bajo condiciones de } \\
\text { estrés climático. } \\
\text { Fallas en una estación de bombeo } \\
\text { no conduce a fallas en el sistema } \\
\text { de distribución. } \\
\text { Red de distribución interconectada, } \\
\text { así una falla local no producirá mayo- } \\
\text { res interrupciones en el servicio. }\end{array}$ & $\begin{array}{l}\text { Los diques pueden } \\
\text { abrirse para inundar } \\
\text { zonas de retención } \\
\text { fuera de la ciudad en } \\
\text { caso de una amenaza. }\end{array}$ \\
\hline
\end{tabular}

Fuente: elaboración propia a partir de Tyler y Moench (2012).

2. Los agentes. La resiliencia en la adaptación de sistemas complejos se apoya fuertemente en los agentes sociales. Tyler y Moench (2012) señalan que la capacidad adaptativa de las organizaciones sociales y de los individuos es un concepto muy relacionado con la resiliencia, porque los aspectos relacionados con esta en la reducción de riesgos de desastres han incluido la flexibilidad, diversidad y capacidad para aprender e innovar. Las capacidades de los agentes sociales son muy importantes en cualquier resiliencia climática urbana y juega un papel muy importante en la toma de decisiones. Los agentes, a diferencia de los sistemas, son capaces de deliberar, hacer análisis independientes, realizar interacciones voluntarias y escoger lo más conveniente ante nuevas informaciones.

Los agentes o actores en los sistemas urbanos son el segundo elemento clave en el marco de resiliencia. Incluye a individuos (agricultores, consumidores), residentes (unidades de consumo, reproducción social, educación, acumulación de capital) y organizaciones del sector público y privado (departamentos de Gobierno, firmas privadas, sociedades civiles). Cada uno tiene sus propios 
intereses identificados y son capaces de cambiar de conducta en función de estrategias, experiencias y aprendizajes. La resiliencia no se extiende homogéneamente en la población de una ciudad, sino que depende crucialmente de las capacidades socialmente diferenciadas de los grupos e individuos. La pobreza, género, etnicidad y edad contribuyen a las vulnerabilidades diferenciadas de los grupos sociales frente a peligros climáticos, y que se expresan en rasgos como calidad de vivienda, localización, acceso a servicios, redes sociales, etc. Para esto se necesita elaborar un mapa de vulnerabilidad de la ciudad de Piura en donde se tengan en consideración a los agentes y no solamente en función de la topografía para el caso de inundaciones.

En resumen, las capacidades de los agentes se pueden medir en las siguientes tres categorías:

a. Responsabilidad. Es la capacidad para organizarse y responder de manera oportuna para prevenir, actuar, y reaccionar frente a desastres. Habilidad para identificar problemas, anticipar, planear y prepararse para un evento disruptivo y responder rápidamente. Aquí la primera respuesta es esperada de las autoridades en sus diferentes niveles, pero también podría pensarse en la organización comunal, quienes crearían un fondo, dentro de sus posibilidades, para atender las emergencias rápidas y no esperar que las autoridades les resuelvan todo.

6. Acumular recursos. Es la capacidad para movilizar varios recursos en respuesta al desastre. También se incluye el acceso financiero no solo local, sino de otros agentes y sistemas mediante colaboraciones preestablecidas.

c. Capacidad de aprendizaje. Es la habilidad para internalizar las experiencias pasadas, evitar repeticiones de errores e innovar para mejorar los resultados; también está aprender nuevas estrategias y tecnologías. Los agentes con mayores capacidades tienen la habilidad de anticipar y actuar para ajustarse a los cambios y presiones ambientales, liderando al resto de miembros de la comunidad. En la tabla 3 se muestran estas categorías aplicadas a un caso concreto. 
Tabla 3. Capacidades de los agentes en la resiliencia frente a las vulnerabilidades climáticas

\begin{tabular}{|c|c|c|c|}
\hline $\begin{array}{l}\text { Capacidades } \\
\text { de agentes }\end{array}$ & $\begin{array}{l}\text { Descripción de } \\
\text { desempeño }\end{array}$ & $\begin{array}{l}\text { Cómo sería esto para el sistema de } \\
\text { abastecimiento de agua, como ejemplo }\end{array}$ & Otros ejemplos \\
\hline 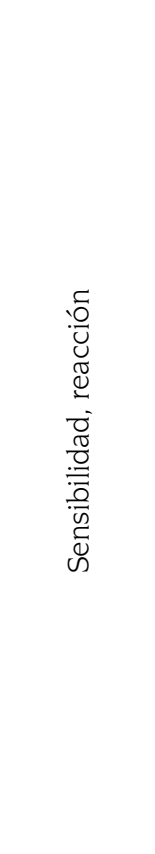 & $\begin{array}{l}\text { Habilidad para orga- } \\
\text { nizar o reorganizar } \\
\text { en un tiempo pru- } \\
\text { dencial; habilidad } \\
\text { para identificar, } \\
\text { anticipar, planear } \\
\text { y preparar a los } \\
\text { actores para una } \\
\text { amenaza, evento } \\
\text { disruptivo o falla } \\
\text { organizacional y } \\
\text { responder inmedia- } \\
\text { tamente después. }\end{array}$ & $\begin{array}{l}\text { Proveedores: } \\
\text { elaboran un plan, capacidades téc- } \\
\text { nicas y otras para la gestión del } \\
\text { agua. Responden rápidamente a } \\
\text { las interrupciones del servicio a los } \\
\text { consumidores o desastres mayores. } \\
\text { Monitorean la condición del sistema } \\
\text { y proveen las finanzas necesarias } \\
\text { para su mantenimiento (detección } \\
\text { de fugas, fuentes de abastecimiento). } \\
\text { Grupos de usuarios: Buscan apoyo } \\
\text { del gobierno y actores en el mer- } \\
\text { cado para mejorar la calidad del } \\
\text { servicio. Identifican fuentes alter- } \\
\text { nativas de abastecimiento de agua } \\
\text { si fuera necesario. }\end{array}$ & $\begin{array}{l}\text { Actores del Gobierno y la } \\
\text { sociedad civil organizan y } \\
\text { responden rápidamente a } \\
\text { las señales de: (1) amenaza } \\
\text { de desastres, (2) impactos } \\
\text { climáticos proyectados y } \\
\text { (3) cambios en las necesi- } \\
\text { dades de las poblaciones. } \\
\text { Catalizan acciones frente } \\
\text { a cambios en las condi- } \\
\text { ciones: si las inundaciones } \\
\text { aumentan, los actores del } \\
\text { Gobierno cambian las regu- } \\
\text { laciones de zonificación, los } \\
\text { mercados cambian las regio- } \\
\text { nes expuestas a usos de baja } \\
\text { vulnerabilidad (agricultura } \\
\text { vs. viviendas), la sociedad } \\
\text { civil invita a reasentamien- } \\
\text { tos. Nuevas organizaciones } \\
\text { locales se forman en función } \\
\text { de necesidad. }\end{array}$ \\
\hline
\end{tabular}

Capacidad para movilizar bienes y recursos para la acción. Esto incluye la habilidad para acceder a recursos financieros y otros bienes, incluyendo aquellos de otros agentes y sistemas, mediante colaboraciones.
Los abastecedores reconocen a autoridades, así como los recursos financieros y técnicos, y los utilizan de manera efectiva. Trabajan proactivamente con otros actores dentro y fuera del gobierno para coordinar temas que cruzan sectores o escalas. Los usuarios movilizan el apoyo para atender temas como calidad del agua o abastecimiento asegurado. Usan sus recursos y redes para acceder a los abastecimientos de agua aun cuando el sistema de agua falle.
Individuos y organizaciones tienen la habilidad para comunicar y acceder a redes sociales para información, finanzas y capacidades. Movilizan las finanzas requeridas para los cambios de modos de vida o modificar las estructuras físicas y sociales en la medida que las condiciones climáticas reducen la viabilidad de las existentes. 
Vulnerabilidad y gestión del riesgo de desastres frente al cambio climático en Piura, Perú

\begin{tabular}{|c|c|c|c|}
\hline $\begin{array}{l}\text { Capacidades } \\
\text { de agentes }\end{array}$ & $\begin{array}{l}\text { Descripción de } \\
\text { desempeño }\end{array}$ & $\begin{array}{l}\text { Cómo sería esto para el sistema de } \\
\text { abastecimiento de agua, como ejemplo }\end{array}$ & Otros ejemplos \\
\hline 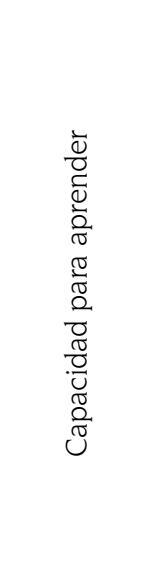 & $\begin{array}{l}\text { Habilidad para inter- } \\
\text { nalizar experiencias } \\
\text { pasadas, evitar repe- } \\
\text { tir errores e innovar } \\
\text { para mejorar el ren- } \\
\text { dimiento. Esto inclu- } \\
\text { ye la capacidad para } \\
\text { acumular y guardar } \\
\text { conocimiento a lo } \\
\text { largo del tiempo. }\end{array}$ & $\begin{array}{l}\text { La experiencia de eventos extremos } \\
\text { es incorporada en las actividades } \\
\text { de planeamiento y capacitación. } \\
\text { Proyecciones de abastecimiento de } \\
\text { agua y escenarios son rutinariamente } \\
\text { incluidos en el planeamiento. Los } \\
\text { planes son revisados regularmente } \\
\text { y refinados en función de nueva in- } \\
\text { formación. La información requerida } \\
\text { es colectada, analizada y socializada. } \\
\text { Los grupos de usuarios regularmente } \\
\text { tienen acceso a la información } \\
\text { sobre recursos de agua y tienen la } \\
\text { capacidad para usarla como base } \\
\text { de un reclamo. }\end{array}$ & $\begin{array}{l}\text { Los planes urbanos son } \\
\text { actualizados en base a es- } \\
\text { cenarios de impacto climá- } \\
\text { tico de largo plazo con la } \\
\text { participación de un amplio } \\
\text { rango de gente informada. } \\
\text { La investigación es usada } \\
\text { para respaldar las decisio- } \\
\text { nes de planificación. }\end{array}$ \\
\hline
\end{tabular}

Fuente: elaboración propia a partir de Tyler y Moench (2012).

1. Instituciones. Pueden ser formales o informales que se crean para mantener las formas de organización social de la sociedad ante un futuro incierto. Las instituciones condicionan en cierta medida las formas de interacción de los agentes y de los sistemas ante el estrés climático (Tyler y Moench, 2012). Un factor importante a tener en cuenta aquí es el costo de los servicios y de salarios aceptados en cada lugar, pues se debe respetar estas estructuras y no crear expectativas que más tarde no se cumplirán y podrían llevar a reclamos, como es el caso de ofrecer salarios por encima de los vigentes en el mercado local. Las instituciones deben apoyar la atención a los grupos urbanos más vulnerables a los cambios climáticos. Un caso común es el reasentamiento de poblaciones urbanas pobres que elimina la vulnerabilidad por la avenida de lodo que destruye las casas; pero esto puede crear otra vulnerabilidad en el nuevo asentamiento como es la falta de salubridad al habitar viviendas transitorias.

La gobernanza, es decir, el proceso de toma de decisiones, es un factor importante que afecta la resiliencia ante desastres. Los procesos de decisión que construyen resiliencia son participativos e inclusivos, permiten a aquellos grupos afectados por un evento climático intervenir en sus soluciones. Tyler y Moench (2012) señalan que la información pública es un componente importante para mantener un ambiente institucional positivo. Las comunidades que tienen acceso a información temprana sobre peligros de desastres están mejor preparadas para responder ante los eventos climáticos, aun en sitios vulnerables, especialmente si son avisados de los lugares de evacuación, rutas y medios de transporte. A 
continuación, en la tabla 4, se especifican las características de las instituciones que promueven la resilencia.

Tabla 4. Características de las instituciones que promueven resiliencia

\begin{tabular}{|c|c|c|c|}
\hline $\begin{array}{c}\text { Rasgos } \\
\text { institucionales }\end{array}$ & $\begin{array}{l}\text { Descripción de } \\
\text { desempeño }\end{array}$ & $\begin{array}{l}\text { Cómo sería esto para el sistema de } \\
\text { abastecimiento de agua, como ejemplo }\end{array}$ & Otros ejemplos \\
\hline 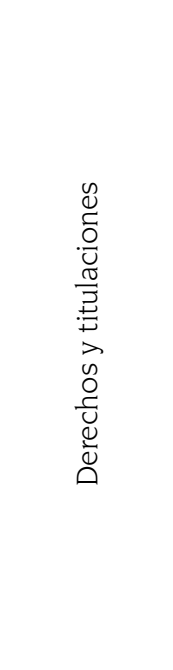 & $\begin{array}{l}\text { Las estructuras de } \\
\text { derechos y titula- } \\
\text { ciones no exclu- } \\
\text { yen a nadie de } \\
\text { su ingreso a sis- } \\
\text { temas críticos o } \\
\text { capacidades. Per- } \\
\text { miten a los gru- } \\
\text { pos que se for- } \\
\text { men, actúen y pro- } \\
\text { mueva el acceso a } \\
\text { recursos básicos. }\end{array}$ & $\begin{array}{l}\text { Los sistemas de abastecimiento de } \\
\text { agua potable hacen que esta sea } \\
\text { accesible para todos los grupos } \\
\text { sociales en la ciudad. Las tarifas de } \\
\text { agua aseguran esta accesibilidad. } \\
\text { Los grupos comunitarios están en } \\
\text { capacidad de organizar estructuras } \\
\text { de gestión del agua en coordinación } \\
\text { con otros actores; colectar fondos e } \\
\text { implementar actividades de gestión. } \\
\text { Individuos particulares y organi- } \\
\text { zaciones tienen derechos bien } \\
\text { definidos con respecto a recursos } \\
\text { de agua, acceso a información, y } \\
\text { están listos a participar con otros } \\
\text { agentes en deliberaciones de polí- } \\
\text { ticas del agua. }\end{array}$ & $\begin{array}{l}\text { Procedimientos simples } \\
\text { que permitan a los grupos } \\
\text { formar organizaciones } \\
\text { legales voluntarias, colec- } \\
\text { tar fondos y emprender } \\
\text { actividades con relación a } \\
\text { necesidades emergentes. }\end{array}$ \\
\hline 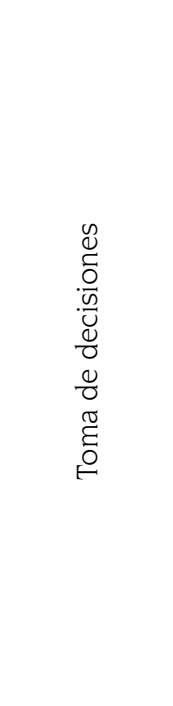 & $\begin{array}{l}\text { Los procesos de } \\
\text { toma de decisio- } \\
\text { nes relacionados } \\
\text { con sistemas cla- } \\
\text { ves urbanos son } \\
\text { transparentes, } \\
\text { representativos y } \\
\text { contabilizables. } \\
\text { Diversos residen- } \\
\text { tes tienen una } \\
\text { forma de proveer } \\
\text { insumos para las } \\
\text { decisiones. Los } \\
\text { procesos de reso- } \\
\text { lución de disputas } \\
\text { son accesibles } \\
\text { y honestos. }\end{array}$ & $\begin{array}{l}\text { Los procesos de distribución del } \\
\text { agua siguen reglas y procedimien- } \\
\text { tos legales claros. Las inversiones } \\
\text { de abastecimiento y distribución del } \\
\text { agua reflejan el interés de todos los } \\
\text { residentes. El proveedor de agua es } \\
\text { tenido en cuenta para legitimar las } \\
\text { agencias del gobierno y puede ser } \\
\text { sancionado por acciones injustifi- } \\
\text { cadas. Existen en el lugar sistemas } \\
\text { formales e informales para mediar } \\
\text { en las disputas que emerjan, sea } \\
\text { que vengan de agencias públicas } \\
\text { o privadas. }\end{array}$ & $\begin{array}{l}\text { Mecanismos para pro- } \\
\text { veer insumos públicos } \\
\text { en las decisiones (con- } \\
\text { vocatorias, mítines, } \\
\text { consultas locales). } \\
\text { Estructuras legítimas exis- } \\
\text { ten para resoluciones } \\
\text { transparentes de disputas } \\
\text { en relación a sistemas } \\
\text { críticos y los agen- } \\
\text { tes que tienen interés } \\
\text { en su gestión. } \\
\text { Están disponibles al pú- } \\
\text { blico los estándares en } \\
\text { varias arenas (protección } \\
\text { ambiental, construcción, } \\
\text { etc.). Normas de libertad } \\
\text { de información. }\end{array}$ \\
\hline
\end{tabular}


Vulnerabilidad y gestión del riesgo de desastres frente al cambio climático en Piura, Perú

\begin{tabular}{|c|c|c|c|}
\hline $\begin{array}{c}\text { Rasgos } \\
\text { institucionales }\end{array}$ & $\begin{array}{l}\text { Descripción de } \\
\text { desempeño }\end{array}$ & $\begin{array}{l}\text { Cómo sería esto para el sistema de } \\
\text { abastecimiento de agua, como ejemplo }\end{array}$ & Otros ejemplos \\
\hline 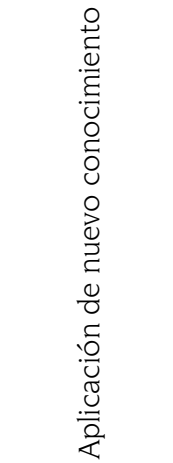 & $\begin{array}{l}\text { Las instituciones } \\
\text { alientan observa- } \\
\text { ciones, aplicación } \\
\text { de evidencias, eva- } \\
\text { luación crítica, y } \\
\text { aplicación de nue- } \\
\text { vo conocimiento. }\end{array}$ & $\begin{array}{l}\text { Agencias de agua apoyan la inves- } \\
\text { tigación aplicada sobre recarga } \\
\text { de agua subterránea, tasas de } \\
\text { salinización e impactos en su abas- } \\
\text { tecimiento. } \\
\text { El proveedor de agua trabaja con } \\
\text { la sociedad civil y el sector pri- } \\
\text { vado para desarrollar estrategias } \\
\text { innovadoras para gestionar los } \\
\text { recursos de agua bajo condiciones } \\
\text { climáticas cambiantes. }\end{array}$ & $\begin{array}{l}\text { Hay procesos recurrentes } \\
\text { que permiten cambios } \\
\text { en códigos y prácticas } \\
\text { estándares como el cam- } \\
\text { bio en las condiciones } \\
\text { climáticas. }\end{array}$ \\
\hline
\end{tabular}

Fuente: elaboración propia a partir de Tyler y Moench (2012).

En Piura, el 63 \% de la población vive en condición de pobreza (AACHCP, 2005, p. 12). El cambio climático traerá trastornos en la economía y formas de vida de la población piurana. La posibilidad de conseguir un desarrollo sostenible en la cuenca del Piura dependerá de la implementación de procesos de adaptación que permitan disminuir los riesgos y aprovechar las oportunidades que ofrece el cambio climático: aumento de humedad, ampliación de la cobertura vegetal en el desierto, aparición temporal de especies ictiológicas de gran valor comercial, condiciones ambientales que favorecen la introducción de nuevos cultivos de valor comercial.

En términos de gestión de las vulnerabilidades frente a los fenómenos ambientales en general, y aplicables a Piura, esta significa i) reforzar los sistemas para reducir su fragilidad ante un evento climático como el FEN, reduciendo sus impactos y la eventualidad de fallas en cascada; ii) construir las capacidades de los agentes sociales para anticipar y desarrollar respuestas adaptativas que permitan acceder y mantener los sistemas urbanos de soporte; iii) identificar y gestionar los factores institucionales que interfieren en las respuestas efectivas para atender la fragilidad del sistema o que impiden la habilidad de los agentes para entrar en acción (Tyler y Moench, 2012, p. 319). A continuación, se incluye una propuesta de intervenciones con resiliencia frente al cambio climático que se puede aplicar para gestionar los riesgos en el departamento de Piura (tabla 5). 
Tabla 5. Propuesta de intervenciones relacionadas con los elementos de resiliencia ante eventos de cambio climático

\begin{tabular}{|c|c|}
\hline resiliencia & $\begin{array}{l}\text { Prioridad de intervenciones propuestas en la resiliencia de ciudades } \\
\text { Flexibilidad en el desarrollo de actividades productivas }\end{array}$ \\
\hline 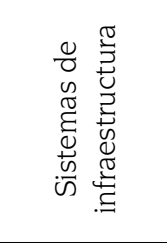 & $\begin{array}{l}\text { Monitoreo de inundaciones y sistemas de alerta temprana } \\
\text { Viviendas resistentes a tormentas e inundaciones } \\
\text { Modelación de estudios hidrológicos e hidráulicos para guiar las inversiones en } \\
\text { prevención de inundaciones } \\
\text { Abrigos contra inundaciones } \\
\text { Cosecha del agua de lluvia }\end{array}$ \\
\hline 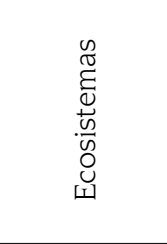 & $\begin{array}{l}\text { Restauración y protección de bosques ribereños } \\
\text { Estabilización de las riberas de los cursos de agua } \\
\text { Manejo de cuencas, protección y recuperación de bosques } \\
\text { Recargas de acuíferos } \\
\text { Planificación de cultivos por adelantado } \\
\text { Agricultura diversificada para disminuir las pérdidas en caso de un evento climático fuerte }\end{array}$ \\
\hline 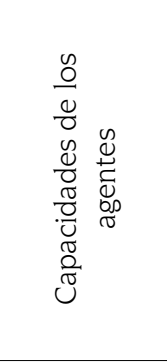 & $\begin{array}{l}\text { Promover y desarrollar sensibilizaciones sobre el cambio climático (talleres, programas } \\
\text { de radio y televisión, teatro) } \\
\text { Incorporar a los actores en el proceso regional de adaptación al cambio climático } \\
\text { Involucrar a las comunidades en la planificación de resiliencias } \\
\text { Introducir temas de cambio climático en el currículo escolar } \\
\text { Entrenar a grupos comunitarios y del gobierno local en la gestión de riesgos de desastres } \\
\text { y respuestas } \\
\text { Mejorar la vigilancia de la salud } \\
\text { Viviendas alternativas para mejorar la calidad de vida de las poblaciones más pobres }\end{array}$ \\
\hline 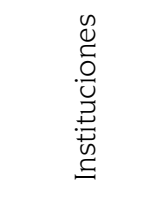 & $\begin{array}{l}\text { Gestión de la demanda de agua } \\
\text { Limitar los derechos de construcciones en las zonas inundables } \\
\text { Mejorar la información pública sobre peligros de inundaciones y evacuaciones } \\
\text { Mejorar los pronósticos del clima y servicios de alarma } \\
\text { Involucrar a las comunidades en la planificación de la resiliencia climática }\end{array}$ \\
\hline
\end{tabular}

Fuente: elaboración propia a partir de Tyler y Moench (2012).

Lo expuesto líneas arriba nos lleva a comprender que la gestión de adaptación al cambio climático es un proceso complejo, en donde es obligatorio ejecutar acciones de prevención y mitigación para reducir los riesgos de desastres. En el caso de Piura como en el resto del Perú, estas acciones se dirigen a los aspectos de reconstrucción de los ecosistemas naturales, infraestructura física rural y urbana de todo tipo. No hay estrategias para formar o capacitar a los agentes sociales, como puede verse en las actividades que viene cumpliendo la Autoridad para la Reconstrucción con Cambios (ARCC) creada por Ley 30556 del 29 de abril de 2017. La ARCC está encargada de liderar, implementar y ejecutar el Plan Integral de Reconstrucción con Cambios (PIRCC) de toda la infraestructura física afectada por el llamado Niño 
Costero de 2017 que se manifestó con lluvias torrenciales que afectaron a nueve regiones del país, entre las que se encuentra Piura. Esta reconstrucción está en pleno proceso de ejecución, y todas las obras son de infraestructura física para mejorar los sistemas de riego, las vías de comunicación, las defensas ribereñas para controlar las inundaciones, construcción de viviendas para los desplazados por las inundaciones, etc. En el caso de la ciudad de Piura, el trabajo se dirige a mejorar las defensas ribereñas del río Piura para evitar las inundaciones, reconstruir las calzadas, reconstruir edificios públicos y otros. La ciudad ya tiene un mapa altimétrico detallado que muestra los sectores bajos que concentran las lluvias, así como la red de desagüe que normalmente se satura debido a que la gradiente de la ciudad es de apenas 2,0 \%. En esta gestión, no se considera la capacitación de los agentes sociales locales para que el proceso sea integral y en cierta manera asumido como propio por los moradores de los lugares. En gran medida, los habitantes de la ciudad de Piura y su vecina Castilla no se sienten identificados con los procesos de reconstrucción porque sienten que es un programa del gobierno en donde las decisiones son tomadas en Lima, con técnicos limeños que a veces tienen poca experiencia en ecosistemas tropicales, como es el caso de Piura.

La recolección de información es un aspecto vital en la gestión del riesgo de los lugares, y en el caso de Piura, felizmente se tiene el soporte de los sistemas de información geográfica que permiten almacenar toda esta información, visualizarla gráficamente y mostrarla en mapas para la comprensión rápida de los fenómenos estudiados y actuar apropiadamente. Además, ya se tiene el apoyo de la red sistema de alerta temprana (SAT-GEO) que enlaza a Bolivia, Ecuador y Perú, y existe una estación de control en Salitral y Querecotillo (valle del Chira) que da la información necesaria para Piura.

El SAT-GEO es una plataforma de apoyo al sistema de alerta de inundaciones implementado por el Programa Regional Andino para el Fortalecimiento de los Servicios Meteorológicos, Hidrológicos, Climáticos y el Desarrollo (Prasdes) en las áreas piloto para servicios climáticos extendidos (Apses) 1 y $2^{5}$. Permite diseñar escenarios de riesgos con base en la información de amenazas como pronósticos meteorológicos y climáticos en tiempo real a través de internet. Su acceso se hace en la web del Ciifen.

Entonces, haciendo un resumen de la gestión de riesgos en Piura, esta puede mejorar si se toma en cuenta lo sugerido por Tyler y Moench (2012), quienes señalan que el riesgo de desastres y la resiliencia debe hacerse identificando tres grupos de componentes: los sistemas, los agentes sociales, y las instituciones. Para eso hay

APSE 1 = lago Titicaca (Puno y La Paz); APSE 2= Catamayo-Chira (Loja y Piura) 
que tener una base de información dinámica que mantenga datos actualizados sobre el estado de los ecosistemas naturales, distribución de los usos del suelo, comportamiento de los procesos de variación climática o cambio climático, actividades de las poblaciones y sus patrones culturales, políticas claras de uso de los recursos y de ubicación de asentamientos humanos, etc. Hay que trabajar en la construcción de las capacidades de los agentes sociales locales para incluirlos en la gestión. Esto permitirá identificar fácilmente las vulnerabilidades y actuar en sus correcciones.

\section{POLÍTICAS PÚBLICAS DEL PERÚ FRENTE AL CAMBIO CLIMÁTICO Y GESTIÓN DE RIESGOS.}

El Perú tiene una larga historia en la adopción de políticas públicas para atender los cambios del clima y sus consecuencias. Está considerado dentro de los países más vulnerables al incremento de temperaturas que llevarían a la desaparición de los glaciares y a una disminución sensible de la biodiversidad entre las más importantes. La sensibilización sobre el cambio climático se inició en Perú más o menos a mediados de la década de 1980 y se dio como respuesta a lo que ya se venía alertando a nivel mundial. Merecen citarse algunos hitos, como la publicación del Primer reporte del panel intergubernamental de cambio climático en 1990 y la Convención de las Naciones Unidas sobre Cambio Climático (CMNUCC) en 1992. En 1993 se estableció en el Perú la Comisión Nacional de Cambio Climático y luego el Consejo Nacional del Ambiente que sirvió de base para la creación del Ministerio del Ambiente en 2008.

Según una publicación de la Sociedad Peruana de Derecho Ambiental y el Congreso de la República (2014), las políticas y normas sobre cambio climático en Perú pueden ubicarse en dos grupos: las que son directamente relevantes para el cambio climático (por ejemplo, adaptaciones o mitigación) y las que son indirectamente relevantes porque contienen alguna referencia menor relacionada con el cambio climático (por ejemplo, normas para prevención de desastres). En el siglo XXI se han multiplicado las normas relacionadas con el cambio climático en cumplimiento muchas veces de los acuerdos internacionales nacidos bajo la tutela de las Naciones Unidas. Así, en 2003 se dio la Estrategia Nacional de Cambio Climático que fue en atención a lo acordado en la CMNUCC de 1992. En vista de que existe una estrecha relación entre los cambios de temperatura y la cubierta vegetal de la superficie terrestre, en el año 2010 se creó el Programa de Conservación de Bosques para la Mitigación del Cambio climático. A nivel ministerial también existe una agenda relacionada con el cambio climático y se vienen elaborando escenarios que buscan diagnosticar los impactos económicos en las finanzas públicas. Los ministerios han incorporado en sus agendas de planificación la dimensión del cambio climático 
en el corto y mediano plazo (Sociedad Peruana de Derecho Ambiental y Congreso de la República, 2014).

En el caso del departamento de Piura o región Piura, el Gobierno Regional publicó la Estrategia regional de cambio climático (2014) en cumplimiento del marco normativo aprobado en el año 2002 y de la Ley Orgánica de Gobiernos Regionales n. 27867. En esta estrategia se reconoce que los principales problemas de Piura en el mediano y largo plazo se relacionan con el cambio climático y que se deben adoptar medidas de adaptación efectivas teniendo en cuenta sus potencialidades para sentar las bases de una economía verde. Esta estrategia regional es el resultado de un proceso articulado con el Ministerio del Ambiente entre los años 2010 y 2011, cuando se publicó la Estrategia nacional de cambio climático, la actualización de la Guía para la elaboración de estrategia regional frente al cambio climático, el Plan de Acción de Adaptación y Mitigación Frente al Cambio Climático, y la Segunda Comunicación Nacional de Cambio Climático.

En esta estrategia regional se han tenido en cuenta los acuerdos internacionales en los que participa el Perú, como son el Convenio de Diversidad Biológica (CBD) de 1992, el Convenio Marco de las Naciones Unidas sobre Cambio Climático (CMNUCC) que entró en vigor en 1994, la Convención Mundial de Lucha Contra la Desertificación que entró en vigencia en 1996 y el Protocolo de Kyoto de 1997. Asimismo, se han considerado los acuerdos y reglamentos nacionales como lo establecido en la Comisión Nacional de Cambio Climático (CNCC) (1993), la Estrategia Nacional de Cambio Climático (ENCC) (2003), la Guía Nacional para la Elaboración de las Estrategias Regionales Frente al Cambio Climático (2008), las Comunicaciones Nacionales de Cambio Climático 2001 y 2010, el Plan de Acción de Adaptación y Mitigación Frente al Cambio Climático (2010), el Plan Estratégico de Desarrollo Nacional-Plan Perú 2021 (2011) y el Plan Nacional de Acción Ambiental (Planaa) Perú: 2011-2021 (2011).

Desde julio del 2008, el Gobierno Regional de Piura creó el Sistema y Programa Regional de Conservación de Áreas Naturales y en el 2010 se formó el Grupo Técnico Regional de Cambio Climático que tiene como finalidad la elaboración de la Estrategia Regional de Cambio Climático (ERCC) de Piura.

La ERCC reconoce que los problemas principales para enfrentar los impactos negativos del cambio climático se relacionan con la reducción de la vulnerabilidad y la adaptación, siendo el eje de todo esto la disponibilidad de agua.

Asimismo, se han aprobado otras ordenanzas que tienen por objeto conservar la biodiversidad y prevenir los riesgos y desastres como consecuencia del cambio climático. Todo esto hace notar que existe en el nivel político una normativa a 
veces detallada frente a las actuaciones en el ambiente regional, solo falta acentuar las actuaciones de manera permanente para prevenir los riesgos y no solo actuar en las reconstrucciones, como es el caso del Programa Reconstrucción con Cambios que se creó a raíz de las inundaciones del año 2017 y que todavía no ha completado su labor.

\section{CONCLUSIONES}

El cambio climático es un proceso constante que viene afectando los ecosistemas naturales y humanos en tanto, no solo se trata de cambios térmicos, sino de las consecuencias que eso produce en la vida de las plantas, animales y humanos. El incremento o escasez de lluvias impacta en la productividad de los ecosistemas que son la fuente del sustento humano. Los efectos de esta ocurrencia son diferentes según se trate de sistemas urbanos o rurales. En el caso de Piura, las lluvias son una bendición para los rurales porque traen agua para sus tierras, en tanto que los urbanos sufren por las inundaciones y las plagas asociadas a la humedad. Las sequías son agradables para los urbanos porque pueden desplazarse sin dificultades y las plagas son casi ausentes, en tanto que los rurales sacan a sus santos patronales rogando a Dios para que llueva.

En esta investigación también se encontró que ya existe una buena literatura sobre la gestión de riesgos ante fenómenos naturales, incluyendo guías y manuales para apoyar a los Gobiernos locales en la gestión de los impactos del cambio climático - por ejemplo, el reporte Usaid (2009) para Estados Unidos; el Programa de Naciones Unidas para los Asentamientos Humanos (ONU-Hábitat, 2011) y otros-. Sin embargo, aquí se ha puesto mayor énfasis en la gestión de medidas de resiliencia incluyendo el mejoramiento de la infraestructura y de las capacidades de respuesta ciudadana. En el caso de Piura se encontró que la debilidad de los programas de gestión de riesgos es que no toman en cuenta a los agentes sociales locales y tampoco hay planes de capacitación. Queda claro que las iniciativas deben ser lideradas por los oficiales administrativos en los diferentes niveles, pero no debemos dejar esa tarea como única responsabilidad de las autoridades, sino que la población debe organizarse para actuar frente a cada evento porque de por medio está en riesgo su supervivencia.

Como ya se mencionó, la prevención es débil porque tal vez no se están viendo las amenazas de manera integral a nivel de cuenca. Se necesita incrementar la forestación en el sector alto de la cuenca del Piura para asegurar la producción de agua de manera sostenida. Asimismo, se necesita realizar estudios técnicos para identificar los lugares en donde se pueda construir pequeñas represas que guarden 
el agua en tiempo de lluvias para utilizarla en los meses de estiaje. No es posible que en la parte baja de Piura que normalmente es desértica y en donde la población saca a sus santos patrones en procesión para pedir a Dios aguaceros, cuando hay lluvia todos se esfuercen en deshacerse del agua limpiando el cauce del río para que esta fluya sin obstáculos hacia el mar. Esa agua debe guardarse para construir pequeñas represas en el piedemonte andino, en donde hay poca agricultura y en ciertos casos son espacios todavía vacíos, que no afectarían en gran medida los intereses agrarios de la población local. En caso de que eso ocurriera, no es muy caro conseguirles una tierra de uso alternativo a los agricultores que resultaran afectados.

Aquí se han propuesto estrategias de gestión que tienen un gran peso en la educación y gobernanza en donde se ponga en práctica los valores de solidaridad en el trabajo, honestidad, justicia y visión de un futuro común digno de ser vivido.

\section{BIBLIOGRAFÍA}

Arana, María Teresa; Quezada, Alicia y Clements, Rebecca (2016). ¿De qué manera los enfoques de género fortalecen el desarrollo compatible con el clima? https://bit.ly/2yaHIXX

Asfaw, Solomon; Coromaldi, Manuela y Lipper, Leslie (2015). Adaptation to Climate Risk and Food Security: Evidence from Smallholder Farmers in Ethiopia. Roma: FAO, 50 p.

AACHCP. Autoridad Autónoma de la Cuenca Hidrográfica Chira-Piura- (2005). Evaluación local integrada y estrategia de adaptación al cambio climático en la cuenca del río Piura. Lima: Consejo Nacional del Ambiente, 108 p.

Banco Mundial (2010). Informe sobre el desarrollo mundial 2010. Desarrollo y cambio climático. Panorama General: Un nuevo clima para el desarrollo. Washington: Banco Mundial, 60 p.

Banco Mundial (2014). Bajemos la temperatura: como hacer frente a la nueva realidad climática. Resumen ejecutivo. Washington: Banco Mundial, 38 p.

Banerjee, Abhijit y Duflo, Esther (2012). Poor Economics: A Radical Rethinking of the Way to Fight Global Poverty. Londres: Hachette, 320 p.

Briones, Fernando (Coord.) (2012). Perspectivas de investigación y acción frente al cambio climático en Latinoamérica. Número especial de Desastres y Sociedad en el marco del XX aniversario de La Red. https://bit.ly/3bCEMkr

Ciifen. Centro Internacional para la Investigación del fenómeno de El Niño (2007). Adaptación y mitigación frente al cambio climático. Quito: Ciifen, 1 p.

Gozzer, Stefania (2019). Cuatro efectos del cambio climático que ya se pueden ver en América Latina. BBC News Mundo. https://www.bbc.com/mundo/noticias-america-latina-50634600

Hoffmann, Dirk (2016). Zimbabue declara "estado de desastre" por sequía. https://www. cambioclimatico-bolivia.org/index-cc.php?pagina $=9$ 
Inrena. Instituto Nacional de Recursos Naturales (2006). Evaluación de la vulnerabilidad física natural futura y medidas de adaptación en áreas de interés en la cuenca del río Piura. Lima: Inrena, $568 \mathrm{p}$.

Janssen, Marco; Bodin, Örjan; Anderies, John; Elmqvist, Thomas; Ernstson, Henrik; McAllister, Ryan; Olsson, Per y Ryan, Paul (2006). Toward a Network Perspective of the Study of Resilience in Social-Ecological Systems. En: Ecology and Society, vol. 11, n. ${ }^{\circ}$ 1, p. 1-20.

Liu, Qingyang; Baumgartner, Jill; de Foy, Benjamin y Schauer, James (2019). A global perspective on national climate mitigation priorities in the context of air pollution and sustainable development. En: City and Environment Interactions, vol. 1, p. 1-10.

Olajide, Oluwafemi y Lawanson, Taibat (2014). Climate change and livelihood vulnerabilities of low-income coastal communities in Lagos, Nigeria. En: International Journal of Urban Sustainable Development, vol. 6, n. ${ }^{\circ}$ 1, p. 42-51.

ONU-Hábitat. Programa de las Naciones Unidas para los Asentamientos Humanos (2011). Global report on human settlements 2011: Cities and climate change. Nairobi: ONU-Hábitat, 279 p.

Sherwood, Amy (2013). Community adaptation to climate change: exploring drought and poverty traps in Gituamba location, Kenya. En: Journal of Natural Resources Policy Research, vol. 5, n. ${ }^{\circ} 2-3$, p. 147-161.

Sociedad Peruana de Derecho Ambiental y Congreso de la República del Perú (2014). Compendio legislativo sobre cambio climático en el Perú (Tomos 1 y 2). Lima: SPDA, 486 p.

Tyler, Stephen y Moench, Marcus (2012). A framework for urban climate resilience. En: Climate and Development. vol. 4, n. ${ }^{\circ}$ 4, p. 311-326.

Usaid -United States Agency for International Development- (2009). Adapting to coastal climate change: A guidebook for development planners. Washington: Usaid, 163 p.

Wheeler, Tim (2014). A changing climate for international development. En: Development in Practice, vol. 24, n. ${ }^{\circ}$, p. p. 465-466.

Yohe, Gary y Tol, Richard (2002). Indicators for social and economic coping capacity - moving toward a working definition of adaptive capacity. En: Global Environmental Change, vol. 12, n. ${ }^{\circ}$, p. $25-40$. 